\title{
Health Care Policy, Finance, and Law
}

\section{Supporting Third-Party Reimbursement: The Legislative Approach}

\author{
$M A R Y$ A. VANDENBOSCH, RN, MS, CDE \\ Catherine McAuley Health Center \\ Ann Arbor, Michigan
}

When all else fails, try the legislative approach.

When informal meetings with thirdparty payors have been ineffective in obtaining a commitment for reimbursement and other attempts such as demonstration projects and direct negotiations have likewise failed, a last resort may be to invoke the power of the law.

Once legislation mandating reimbursement has been successfully introduced, you, as a leader in the field, may be requested to support the cause and perhaps even to testify. How do you start? What should you do?

Preparation is the key. The legislative process is very complex, time-consuming, and often unpredictable. Your political effectiveness may in part depend on how well you've done your homework. To prepare yourself for this very important arena of legislation, the following steps are offered for your consideration.

- Identify your supporters. What group has been mainly responsible for introduction of the bill? Who are the leaders in the field of diabetes in your state? You may readily identify local chapter members of the American Diabetes Association and your state members of the American Association of Diabetes Educators as those who will support your goals, but do you know their formal position statement on the issue (or if they have one)? What about other groups in the community who might be interested in seeing your legislation pass? Create a network of support.

- Select a single coordinator. It is important that the resources of all agencies interested in seeing the legislation pass are utilized effectively and efficiently. The coordinator can help direct and focus the lobbying activities of the group. Spokespersons for various agencies should be selected based on their credibility and respect within the community as well as on their ability to articulate the issues well, particularly under pressure. Many informal meetings should be held prior to giving any testimony. Issues should be clearly understood and the various leaders should speak with a unified voice.

- Know the legislative process. The sequence by which a bill becomes a law can be very complex. Bills must pass through several committees before enactment. If this is your first involvement with the legislature, you could get bogged down in your efforts unless you understand the process thoroughly. Visit your local library or dust off your books from your high school government class.

- Identify kev leaders in the legislature. Find out which legislators support your cause and what committees they sit on. Are they likely to be influential? Make appointments to meet with your own senators and representatives to help them understand your position and to gain their support. Remember they are your elected officials. They work for you. Be clear and concise in your conversations and follow up with a summary letter for their files.

- Know the issues. Keep yourself well-informed. Spend time researching what has been done about this same issue in the past. Why should you be reimbursed for your diabetes education program? Are there documented published studies to prove its costeffectiveness? Get copies. Be prepared to quote them. Educate yourself on all aspects of the issue, including technical information. Be prepared to answer all questions with clarity and simplicity. Know facts and keep a fact sheet handy.
Know the opposing view. What stance did your adversaries take in the past? What objections are they likely to raise now? Can you present facts to counter their claims? You are likely to be more influential with the legislators if you raise the objections first and diffuse them rather than have them introduced for the first time by those representing the opposing side.

- Prepare your testimony well. When you are requested to testify at a special hearing, take the time to organize your presentation in an appropriate and effective manner. If others in your coalition have already testified, request copies of their testimony. Meet with others who will be testifying with you. Compare notes and present a unified view.

1. Present your testimony in an accepted form. If you have never testified before, seek assistance with the format. Be very clear about whom you are representing and whether you are for or against the proposed legislation. Most testimonies can begin by simply stating "I am here today representing (organization), a (describe the organization: eg, a 400-member organization of diabetes educators in the state of ___). and to testify in support of mandatory third-party reimbursement for outpatient diabetes education." Next, make a statement or two establishing your credibility, then proceed to describe the rationale for your position. Use factual data and quote when possible. Be sure to state the source of your references. Avoid using anecdotal cases or rare occurrences to make a point. End by thanking the committee for their time and the opportunity to address them.

In most cases you will be allowed approximately two to five minutes to make your presentation. Having your testimony in written form that you can read 
will help you to be efficient and thorough, especially if you are nervous in addressing a large group. The committee may ask you questions, but you will not be given an opportunity to question the committee, nor can you question or rebut presenters who follow you. Therefore, make your presentation count.

2. Be prepared to modify your testimony. You will not have any control over the order of the presentations. In essence, a card with your name on it is randomly selected. If you are lucky enough to be one of the last presenters, you can modify your testimony to rebut earlier negative presentations. The committee is likely to remember the remarks of the last presenter. I suggest that you make your changes in writing on your typed copy. When you are ready to testify, read your corrected copy. All of your comments are a matter of public record. You will be requested to give a copy of your testimony to the committee. but it is not necessary to give it to them on the spot. Mail them a copy of the corrected version.

3. Keep your composure. Testify in a clear voice and emphasize important points. Avoid emotionalism.

- Continue to lobby and be patient. Keeping the issues alive in the minds of the legislators and the media over long periods of time can be tedious but is necessary to make an impact. Legislators whose phones are ringing off the hook and whose mailboxes are filling up are bound to respond. Don't expect immediate success. The legislative process is slow and deliberate. Timing is everything. Other factors may be working against you, such as a changing economic environment. Even though the timing for passage is unfavorable now, the legislation may pass easily in the future when the climate is more favorable.

One last word of caution: don't get so taken up with the process that you forget the goal. In one state, Medicaid agreed to reimburse for outpatient education based on the testimony given at the State Insurance Commissioner's hearingbefore legislative action was ever taken. 